\title{
Spatial Memory Deficits, Increased Phosphorylation of the Transcription Factor CREB, and Induction of the AP-1 Complex Following Experimental Brain Injury
}

\author{
Pramod K. Dash, ${ }^{1}$ Anthony N. Moore, ${ }^{1}$ and C. Edward Dixon ${ }^{2}$ \\ 'Department of Neurobiology and Anatomy and 'Department of Neurosurgery, University of Texas-Houston Health \\ Science Center, Houston, Texas 77225
}

\begin{abstract}
Traumatic brain injury causes both short- and long-term neurological impairments. A cascade of biochemical changes triggered by the injury may increase the expression of several genes, which has been hypothesized to contribute to the observed cognitive deficits. The mechanism(s) of induction for these genes is not yet known. We present evidence that lateral cortical impact injury in rats that produces spatial memory deficits also increases phosphorylation of the transcription factor CREB (CAMP response element binding). Subsequent to the phosphorylation of CREB, c-Fos expression and the AP-1 complex are enhanced. The temporal and spatial activation of C-Fos is consistent with it being induced by phosphorylated CREB proteins. Thus, CREB-mediated gene activation may contribute to the observed behavioral deficits. Further elucidation of the biochemical and pathophysiological changes will be of importance for clinical therapy.
\end{abstract}

[Key words: cortical impact, spatial memory deficit, hippocampus, transcription factors, CREB, AP-1, c-Fos]

Traumatic brain injury (TBI) causes transient as well as longlasting pathophysiological changes in brain function. The acute pathophysiological responses include depolarization, neurotransmitter release, excessive neuronal excitation, and physical alteration to neurons by contusion (for review see Hayes et al., 1992). Long-lasting changes include deficits in motor and spatial memory performances. Acute changes can alter intraccllular signal transduction pathways which may contribute to chronic neuronal dysfunction. Transmitter release and neuronal excitation can activate several protein kinases that have been shown to be important for intracellular signaling and memory storage (O'Dell et al., 1991; Silva et al., 1991a,b; Grant et al., 1992; Frey et al., 1993). Stimulation of protein kinases can modulate the activity of transcription factors via protein phosphorylation (Yamamoto et al., 1988; Dash et al., 1991; Sheng et al., 1991). Activation of these transcription factors alters the expression of late-effector

Received May 23, 1994; revised July 12, 1994; accepted Sept. 14, 1994.

We thank Drs. Neal Waxham, Arnold Eskin, and John Byrne for their comments on the early drafts of this manuseript. We thank Drs. David Ginty and Marc Montminy for their generous gifts of the phosphoCREB and CREB antibodies, respectively. We also thank Dr. Ronald Hayes for his continued support. This work was supported in part by a fellowship from the Klingenstein Foundation, MH49962, NS31998, CDC-R49 CCR606659, and by an ARP grant from the Texas Higher Education Board.

Correspondence should be addressed to Pramod K. Dash, Department of Neurobiology and Anatomy, University of Texas-Houston Health Science Center, P.O. Box 20708, Houston, TX 77225.

Copyright (c) 1995 Society for Neuroscience 0270-6474/95/152030-10\$05.00/0 genes, which may change the functional properties of nerve cells (Goelet et al., 1986; Morgan and Curran, 1991). Therefore, it is possible that the functional deficits observed following TBI may be, in part, attributable to the pathophysiologic exprcssion of specific neuronal late-effector genes activated by these kinases.

The cyclic adenosine monophosphate (cAMP) response element binding protein (CREB) is a member of the ATF (activating transcription factor) family of proteins. CREB mediates the expression of several immediate-early genes (IEGs) in response to agents that increase intracellular concentrations of cAMP or $\mathrm{Ca}^{21}$ (Montminy et al., 1986; Hymann et al., 1988; Hoeffler et al., 1989; Dash et al., 1991; Sheng et al., 1991). These signals trigger the phosphorylation of CREB on serine ${ }^{133}$ (Gonzalez et al., 1989). This phosphorylation event induces transcription of genes containing CRE (cAMP response element) sequences such as the proto-oncogene $c$-fos (Sheng and Greenberg, 1990), tyrosine hydroxylase (Kim et al., 1993), and growth factors (Hawley et al., 1992). The Fos protein can dimerize with the members of the Jun family of proteins to form a transcriptional regulatory complex known as activating protein 1 (AP-1) (Bohmann et al., 1987; Angel et al., 1988; Rauscher et al., 1988; Sassone-Corsi et al., 1988). Fos and Jun family members can be induced in specific sets of neurons in the brain by many stimuli (Sonnenberg et al., 1989a; Kornhauser et al., 1990; An et al., 1993). It is thought that specific combinations of these IEGs cause distinct long-term changes in neuronal function in response to stimuli (Morgan and Curran, 1991).

In this report, we have used a rat cortical impact model of TBI to determine if injury with magnitudes that produce chronic spatial memory performance deficits in a Morris water maze task (Morris et al., 1986) also increase CREB phosphorylation and trigger IEG expression. We have used antibodies which specifically detect phosphorylated CREB to examine the activation of this protein (Ginty et al., 1993). Using this antibody, we report that the phosphorylation of CREB is increased 5 min after cortical impact and decreases to control levels after $30 \mathrm{~min}$. The expression of c-Fos and the AP-1 complex was enhanced subsequent to CREB phosphorylation. These data suggest that chronic post-traumatic disturbances may be related to CREBmediated gene activation.

\section{Materials and Methods}

Materials. c-Fos and c-Jun antibodies were purchased from Santa Cruz Biotech, California, microcystin-LR was purchased from Calbiochem, and rats were purchased from Harlan Sprague-Dawley.

Impact device. The apparatus for controlled cortical impact injury (Dixon et al., 1991) consisted of a small $(1.975 \mathrm{~cm}$ )-bore, double-acting, 
stroke-constrained, pneumatic cylinder with a $5.0 \mathrm{~cm}$ stroke. The cylinder was rigidly mounted perpendicular to the cortex on a crossbar. The lower rod end had an impacter tip attached (i.e., that part of the shaft that comes into contact with the exposed dura matter). The upper rod end was attached to the transducer core of a linear variable differential transformer (LVDT). The velocity of the impacter shaft was controlled by gas pressure. Impact velocity was directly measured by the LVDT (Shaevitz model $500 \mathrm{HR}$ ), which produces an analog signal that was recorded by a PC-based data acquisition system (R.C. Electronics) for analysis of time/displacement parameters of the impacter.

Production of cortical impact brain injury. A total of 70 male Sprague-Dawley rats were initially anesthetized with $4 \%$ isoflurane with a $2: 1 \mathrm{~N}_{2} \mathrm{O}: \mathrm{O}_{2}$ mixture in a vented anesthesia chamber. All protocols were in compliance with the NIH's Guide for the Care and Use of Laboratory Animals and approved by the Institutional Animal Care and Use Committee. Following endotracheal intubation, rats were mechanically ventilated with a $2 \%$ isoflurane and $2: 1 \quad \mathrm{~N}_{2} \mathrm{O}: \mathrm{O}_{2}$ mixture. Animals were mounted in the injury device sterentax ic frame in a supine position secured by ear bars and incisor bar. The head was held in a horizontal plane with respect to the interaural line. A midline incision was made, the soft tissues reflected, and a $6 \mathrm{~mm}$ craniotomy was made midway between the bregma and the lambda with the medial edge of the craniotomy $1 \mathrm{~mm}$ lateral to midline. An identical craniotomy was also made contralateral to the impact site. Cortically impacted rats received a single impact at $6 \mathrm{~m} / \mathrm{sec}, 2.5 \mathrm{~mm}$ deformation. Sham rats underwent identical surgical procedures but were not injured. Core body temperature was monitored continuously by a rectal thermistor probe and maintained at $37-38^{\circ} \mathrm{C}$. After injury, the scalp was sutured closed and the animal extubated to minimize the anesthetic effects on the acute neurological assessments.

Acute neurological assessments. A battery of tests that had been shown to be sensitive to varying magnitudes of brain injury in the rat were employed to confirm that the injury magnitude used in the biochemical studies was comparable to that used in the water maze study (Smith et al., 1991; Hamm et al., 1992). Assessments of simple nonpostural somatosensory functions were conducted by recording the duration of suppression of a response to stimulation. The corneal reflex was evaluated by lightly touching the cornea with a cotton swab to elicit an eyeblink. Assessments of simple postural somatomotor functions included measurements of the duration of suppression of flexion reflexes to stimulation. The assessment of the paw and tail flexion reflexes consisted of the gradual application of pressure on the contralateral hindpaw or tail until paw or tail withdrawal was noted. More complex, postural somatosensory function was assessed by recording the duration of suppression of the righting response. The righting response was defined as the animal's ability to right itself three times consecutively after being placed on its back.

Chronic neurological assessments. Gross vestibulomotor function was assessed using a beam-balance task which consisted of placing the animal on a suspended narrow wooden beam $(1.5 \mathrm{~cm}$ wide) and measuring the duration it remains on the beam for up to $60 \mathrm{sec}$. Training consists of three trials, which served as baseline measures. Finer components of vestibulomotor function and coordination were assessed using a beam-walking task (Dixon et al., 1991). Two days prior to injury, rats were trained to escape a bright light and loud white noise (Heath model AD-1309) by traversing a narrow wooden beam $(2.5 \times 100.0$ $\mathrm{cm}$ ) to enter a darkened goal box at the opposite end of the beam. During training and testing, animals were placed at one end of the beam close to the source of light and noise. The noise and light were terminaled when the rat entered the goal box at the opposite end of the beam. Four steel pegs $(3.0 \mathrm{~mm}$ diameter, $4.0 \mathrm{~cm}$ high) were placed in an alternating sequence along the beam to increase the difficulty of the task. Performance was assessed by measuring the animal's latency to traverse the beam. Data for each session consisted of the mean of three trials. The animal remained in the goal box for $30 \mathrm{sec}$ between trials.

Morris water maze procedure. The water maze employed a pool that is $180 \mathrm{~cm}$ diameter and $60 \mathrm{~cm}$ in depth. The pool was painted black and filled with water to a depth of $28 \mathrm{~cm}$. A clear plexiglass platform $10 \mathrm{~cm}$ in diameter and $26 \mathrm{~cm}$ high (i.e., $2 \mathrm{~cm}$ below the water's surface) was used as the hidden goal platform. The pool was located in a $2.5 \times$ $2.5 \mathrm{~m}$ room with numerous extramaze ques that remained constant throughout the experiment. Testing started $10 \mathrm{~d}$ postinjury to avoid the observed motor deficits, and continued for four additional days. Rats were given four trials per day for five consecutive days to establish baseline performance. For each daily block of four trials, rats were placed in the pool by hand facing the wall. Rats started a trial once from each of the four randomized possible start locations (north, east, south, west). The goal platform was positioned $45 \mathrm{~cm}$ from the outside wall and placed in the northwest quadrant of the maze. Rats were given a maximum of $120 \mathrm{sec}$ to find the hidden platform. If a rat failed to find the platform after $120 \mathrm{sec}$, it was placed on the platform by the experimenter. All rats were allowed to remain on the platform for 30 sec before being placed in a $37^{\circ} \mathrm{C}$ incubator between trials. The intertrial interval was $4 \mathrm{~min}$. These rats were subsequently used for in vivo microdialysis studics.

Preparation of nuclear extracts. At various times following cortical impact, animals were decapitated by a guillotine. The cortical and the hippocampal tissue were quickly removed in oxygenated ice-cold artificial cerebrospinal fluid (CSF: $10 \mathrm{~mm}$ HEPES, $\mathrm{pH} 7.2,1.3 \mathrm{~mm}$ $\mathrm{NaH}_{2} \mathrm{PO}_{4}, 3 \mathrm{~mm} \mathrm{KCl}, 124 \mathrm{~mm} \mathrm{NaCl}, 10 \mathrm{~mm}$ dextrose, $26 \mathrm{~mm} \mathrm{NaHCO}_{3}$, $2 \mathrm{mM} \mathrm{CaCl}_{2}$, and $2 \mathrm{mM} \mathrm{MgCl}_{2}$ ). Sample preparation was carried out at $4^{\circ} \mathrm{C}$. The tissues were separately homogenized (10 strokes) in five volumes of a buffer containing $15 \mathrm{~mm}$ HEPES, $\mathrm{pH} 7.2,0.25 \mathrm{M}$ sucrose, $60 \mathrm{~mm} \mathrm{KCl}, 10 \mathrm{~mm} \mathrm{NaCl}$, plus protease inhibitors (1 mM EGTA, $5 \mathrm{~mm}$ EDTA, and $1 \mathrm{mM}$ PMSF) and phosphatase inhibitors ( $2 \mathrm{~mm} \mathrm{NaF}, 2 \mathrm{~mm}$ $\mathrm{NaPP}_{i}$, and $5 \mu \mathrm{M}$ microcystin-LR) in a dounce homogenizer using a loose pestle. The cells were then pelletized at $2000 \times g$ for $10 \mathrm{~min}$. To lyse the cells, the pelletized material was incubated in five volumes of 10 IIM HEPES, pH 7.2, 1.5 IIM $\mathrm{MgCl}_{2}, 10$ mм KCl, 1 пाм PMSF, 5 $\mu \mathrm{M}$ microcystin-LR, $2 \mathrm{mM} \mathrm{NaF}$, and $2 \mathrm{mM} \mathrm{NaPP}$ for $5 \mathrm{~min}$. The cell suspension was homogenized (seven strokes) in a dounce homogenizer using the tight pestle. The nuclei were pelletized at $4000 \times g$ for 10 min. The nuclei were lysed in one bed volume of $100 \mathrm{mM}$ HEPES, $\mathrm{pH}$ 7.2, $1.5 \mathrm{mM} \mathrm{MgCl}_{2}, 1 \mathrm{~mm}$ EDTA, $0.8 \mathrm{M} \mathrm{NaCl}, 25 \%$ glycerol, $2 \mathrm{~mm}$ $\mathrm{NaF}, 2 \mathrm{mM} \mathrm{NaPP}, 1 \mathrm{~mm}$ PMSF, and $5 \mu \mathrm{M}$ microcystin-LR by gentle rocking for $30 \mathrm{~min}$. Cell debris and genomic DNA were removed by centrifugation at $14,000 \times g$ for $30 \mathrm{~min}$. The supernatant solution was removed and frozen. For studies involving CREB phosphorylation and c-Fos induction, the sham animals were killed at $5 \mathrm{~min}$ and $1 \mathrm{hr}$ postinjury, respectively.

Western blots. The nuclear extracts were diluted in water to reduce the salt concentration to approximately $100 \mathrm{mM}$. The amount of protein in each sample was measured using a MicroBCA assay (Pierce). Samples were prepared by boiling in sample buffer and equal amounts of protein were separated on a $8.5 \%$ SDS PAGE. The proteins were transferred to an Immobilon-P membrane (Millipore) using a semidry transfer apparatus (Millipore). Western blots using the various antibodies were carried out as described previously (Harlow and Lane, 1988). The blots were visualized using an alkaline phosphatase chemiluminescence detection system (GIBCO-Bethesda Research Labs) which allowed the production of multiple fluorographs with different lengths of exposure. The quantification of the immunoreactive bands was carried out utilizing a Bio-Rad model GS-670 Imaging Densitometer. The Western blot data was repeated in at least three independent experiments.

Gel-retardation assay. Equal amounts of the nuclear extracts were used for gel-retardation assays using either the CRE (cAMP response element) or TRE (TPA response element) sequences as probes. The CRE probe was made using an oligonucleotide from the rat somatostatin gene sequence 5'-GGCCTCCTTGGCTGACGTCAGAGAGAGAGTTCTGCA-3' and its complementary sequence (Montminy et al., 1986). The AP-1 probe was synthesized using the metallothionein gene sequence 5'-GATCTGTGAGTCAGCGCGA-3' and its complementary sequence (Lee et al., 1987). The assays were carried out essentially as described by Dash and Moore (1993) with the following minor modifications. Four microliters of each extract containing $5 \mu \mathrm{g}$ of protein was added to $16 \mu \mathrm{l}$ of a reaction mixture consisting of $10 \mathrm{mM}$ Tris-Cl, pH 7.9, $10 \mathrm{~mm} \mathrm{KCl,} 0.5 \mathrm{~mm}$ EDTA, $5 \mathrm{~mm} \mathrm{MgCl}_{2}, 5 \%$ glycerol, $5 \%$ sucrose, $1 \mu \mathrm{g}$ each of sonicated salmon sperm DNA and poly (dI-dC), $1 \mathrm{mM}$ DTT, and $0.5 \mathrm{ng}$ of ${ }^{32} \mathrm{P}$-labeled probe. For gel supershift assays, the nuclear extracts were preincubated with $0.7 \mu \mathrm{g}$ of antibodies in the absence of any thiol reagent for $15 \mathrm{~min}$ at room temperature. For competition with oligonucleotides, the cold competitors were added to the reaction mixture prior to the addition of protein extracts. The gel-retardation assays were repeated in three independent experiments.

Immunohistochemistry. Following cortical impact, animals were anesthetized with an intraperitoneal injection of $0.7 \mathrm{ml}$ of $64.8 \mathrm{mg} / \mathrm{ml}$ sodium pentobarbital. After animals failed to respond to foot pinch, they were perfused with $100 \mathrm{ml}$ of phosphate-buffered saline (PBS). The brain tissue was fixed by perfusing with $150 \mathrm{ml}$ freshly prepared $4 \%$ paraformaldehyde and $15 \%$ picric acid in PBS. The brains were re- 
Table 1. Mean acute postinjury neurological responses

\begin{tabular}{llll} 
Response & $\begin{array}{l}\text { Water maze } \\
\text { study }\end{array}$ & $\begin{array}{l}\text { Biochemical } \\
\text { study }\end{array}$ & $p$ \\
\hline Right hindpaw flexion & $1.55 \pm 0.08$ & $1.78 \pm 0.06$ & NS \\
Left hindpaw flexion & $1.55 \pm 0.08$ & $1.56 \pm 0.08$ & NS \\
Tail pinch flexion & $1.66 \pm 0.09$ & $1.66 \pm 0.07$ & NS \\
Corneal & $1.55 \pm 0.08$ & $1.78 \pm 0.06$ & NS \\
Righting & $3.89 \pm 0.15$ & $3.74 \pm 0.15$ & NS
\end{tabular}

The response time for the reflexes was measured immediately after impact as described in Materials and Methods. Time is given in minutes \pm SEM.

moved and postfixed for $2 \mathrm{hr}$ in $4 \%$ paraformaldehyde and $15 \%$ picric acid in PBS. The tissue was trimmed and then placed in $30 \%$ sucrose in PBS overnight at room temperature. Tissues were briefly dried to remove any surface liquid and imbedded with OCT (Myers Laboratory). Fifty micron slices were prepared using a cryostat. The immunohistochemistry using these slices was carried out using an avidin-biotin detection system from Vector Laboratory essentially as suggested by the supplier. For the detection of phosphorylated CREB proteins, hippocampi were removed quickly, as described above (Preparation of nuclear extracts). The tissues were fixed in cold $4 \%$ paraformaldehyde and $15 \%$ picric acid in PBS for 8-10 hr. The sectioning and immunohistochem istry were carried out as described above. For immunohistochemistry studies for CREB phosphorylation and c-Fos expression, the sham animals were killed at $5 \mathrm{~min}$ and $1 \mathrm{hr}$ postinjury, respectively. Immunohistochemistry was repeated in four independent experiments.

Statistical analysis. Student's $t$ test was used for comparisons between groups for acute neurological responses and Western blots. For behavioral studies, a repeated measures analysis of variance (ANOVA) was utilized to determine group main effects. A Tukey post hoc $t$ test was used to determine group differences on specific days postinjury. Differences were considered statistically significant when $p<0.05$.

\section{Results}

\section{Neurologic responses}

We first evaluated acute neurological responses occurring immediately after the injury. The durations of suppression of both simple and complex somatosensory functions were not significantly different between animals injured for the water maze study and the biochemical studies (Table 1). Therefore, the injury magnitudes are likely to be equivalent between the two studies.

Figure $1 A$ illustrates the latency to balance on a beam on days $1-4$ postinjury. Injured animals showed significant (injured $=$ $33.5 \pm 5.7 \mathrm{sec}$ vs sham $=60 \pm 0.0 \mathrm{sec}, p<0.01)$ decreases in the balance durations on day 1 postinjury. However, after day 1 there was no significant difference in the latency between sham and injured animals. Figure $1 B$ illustrates the latency to traverse the walking beam on days $1-4$ postinjury. Injured animals showed significant (injured $=48.7 \pm 5.6 \mathrm{sec}$ vs sham $=$ $5.6 \pm 0.23 \mathrm{sec}, p<0.01)$ increases in beam-walking latencies on days 1-3. By day 4 , the walking latencies of the injured group did not differ significantly from the sham group. Thus, both the beam-balance and the beam-walking tests show that the vestibular motor deficits have returned to the control values by $4 \mathrm{~d}$ postinjury.

\section{Spatial memory deficits}

Figure $1 C$ illustrates the latency to find the hidden platform over a $5 \mathrm{~d}$ testing period beginning $10 \mathrm{~d}$ after injury in order to avoid any contribution from vestibular motor deficits. The mean latency of the four daily trials was calculated for each animal. The ANOVA indicated a significant group main effect on the latency to reach the hidden platform $\left(F_{1,19}=6.87, p<0.016\right)$, indicating

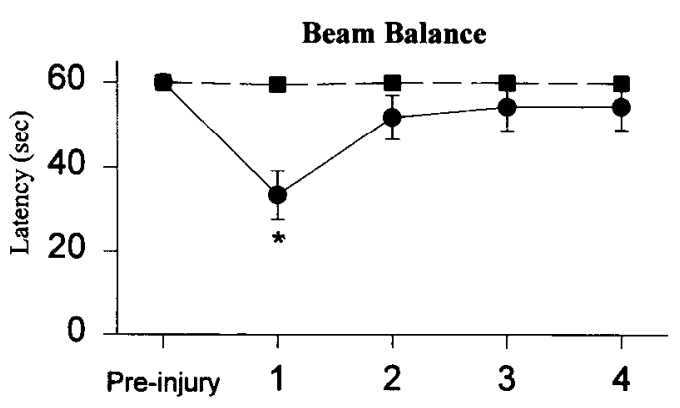

$\mathbf{A}$

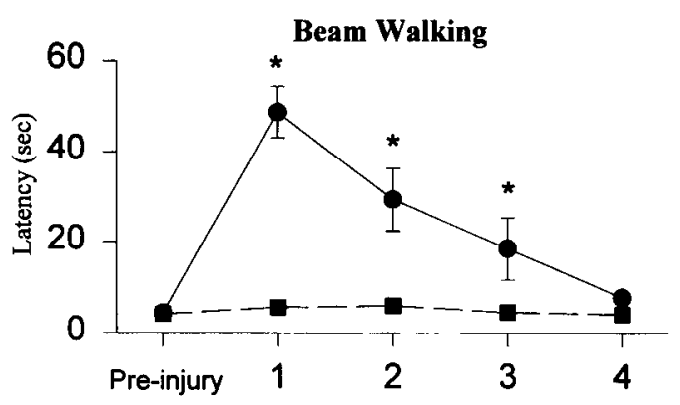

C

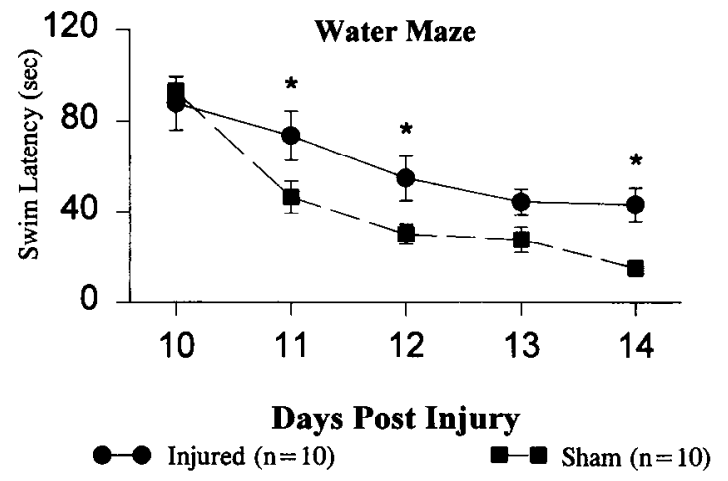

Figure 1. Functional deficits following lateral cortical impact injury. $A$, Latency to balance on a beam across days postinjury. Prior to injury the animals were tested on their ability to balance up to $60 \mathrm{sec}$ on a beam. One day following injury, beam-balance latencies were measured daily for four consecutive days. Injured animals showed a significantly shorter latency at $1 \mathrm{~d}$ postinjury than sham animals. $B$, Latencies to traverse a beam across days postinjury. Prior to injury, animals were trained to traverse the beam within $5 \mathrm{sec}$. One day following injury, beam-walking latencies were measured daily for four consecutive days. Injured animals showed significantly longer latencies to traverse the beam on days 1-3 than sham-injured animals. $C$, Latency to locate a hidden platform in the Morris water maze on days $10-14$ postinjury. Injured animals showed significantly longer latencies to locate the platform than the sham animals. ${ }^{*} p<0.01$.

that the injured group has longer swim latencies than the sham group. On the first day of testing there was no difference between the two groups, suggesting equivalent swimming performances. At this magnitude of injury, when the platform is removed, the injured animals spend less time than sham animals in the quadrant which previously contained the platform (data not shown). Thus, this magnitude of injury produces increased latencies in the water maze task that are likely attributable to spatial memory deficits. Using injury levels that produce behavioral deficits, we next investigated some of the acute biochemical changes which could cause changes in gene expression. Specifically, we examined the activation of the transcription factor CREB and the immediate-early genes $c$-fos and $c$-jun. 
A.

\section{Hippocampal}

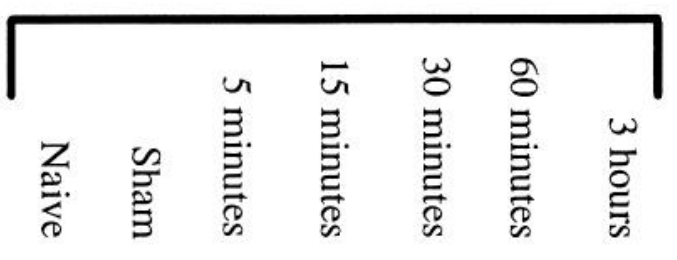

C.

Hippocampal

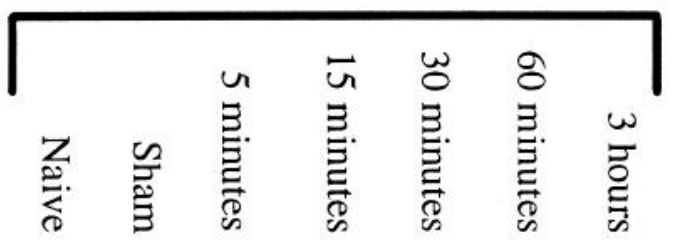

$49.5 \mathrm{kDa}---$
B.

\section{Cortical}

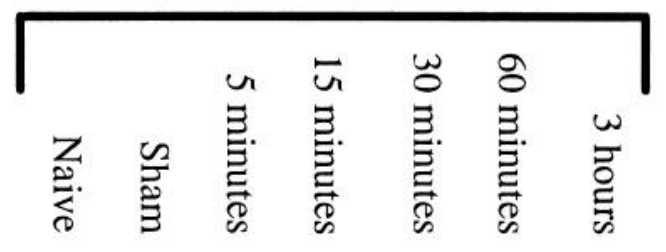

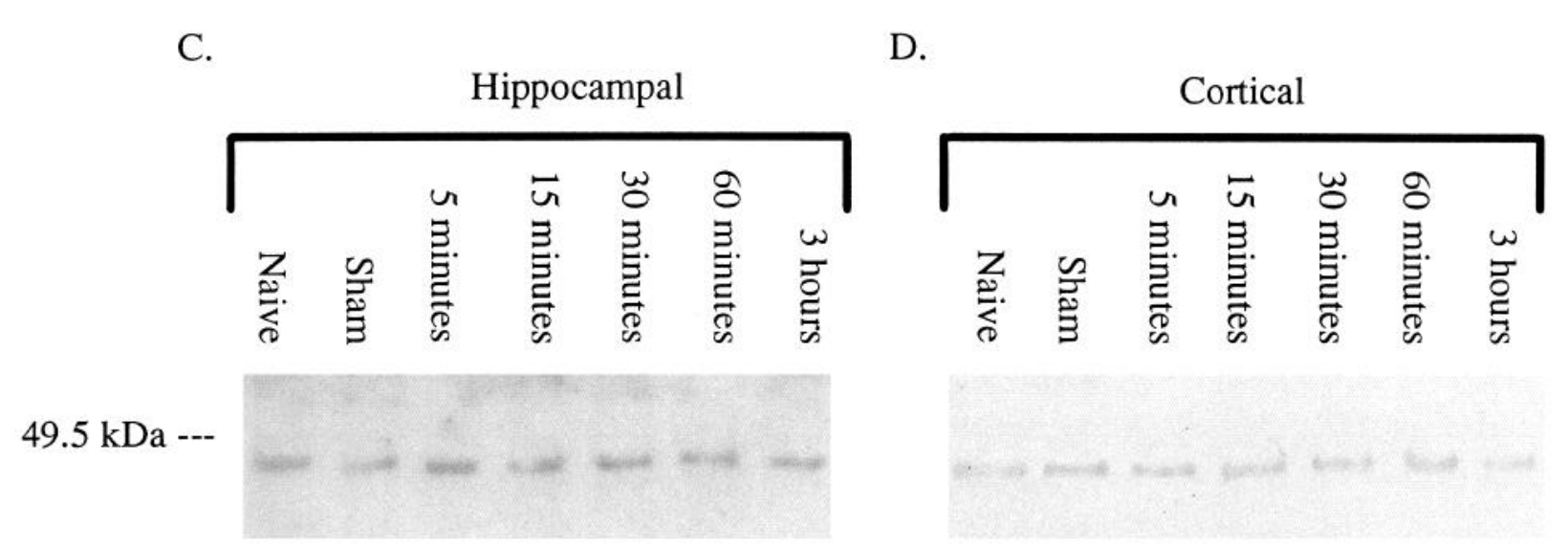

Figure 2. Increased phosphorylation of CREB in the hippocampal and cortical tissues following cortical impact injury. A, A representative Western blot showing the time course of CREB phosphorylation following cortical impact in the ipsilateral hippocampus. Nuclear extracts were prepared as described in Materials and Methods. Five micrograms of each extract were separated on a 8.5\% Tris/Tricine gel and transferred to an Immobilon-P membrane. Phosphorylated CREB protein was detected using an antibody specific to CREB only when phosphorylated on serine ${ }^{133}$. The phosphorylation of CREB is maximal $5 \mathrm{~min}$ after the injury. $B$, A representative Western blot showing the time course of CREB phosphorylation following cortical impact in the cortex surrounding the site of injury. Nuclear extracts were separated and the phosphorylated CREB was visualized as in $A$. CREB is maximally phosphorylated between 5 and 15 min after the injury. $C$, A representative Western blot showing the total amount of CREB protein following cortical impact in the ipsilateral hippocampus. Nuclear extracts were separated and the total amount of CREB was visualized using an antibody which detects CREB proteins independent of their phosphorylation state (Yamamoto et al., 1988). The blot shows that there is no significant change in the amount of CREB protein up to $1 \mathrm{hr}$. D, A representative Western blot showing the total amount of CREB protein following cortical impact in the cortex surrounding the site of injury. Total CREB was detected as in $C$. There is no significant change in the amount of CREB at the time points examined.

\section{Increased CREB phosphorylation by Western blot}

Using an antibody that detects CREB protein only when phosphorylated on serine ${ }^{133}$ (Ginty et al., 1993), we examined the levels of phosphorylation in the ipsilateral hippocampal and cortical cells. The degree of CREB phosphorylation in naive and sham animals are shown in the first and second lanes of Figure 2, $A$ and $B$, respectively. Phosphorylation is increased within $5 \mathrm{~min}$ of injury in the hippocampus. Densitometry of the Western blots showed an average $104 \%$ increase at $5 \mathrm{~min}$ postinjury compared to naive (naive $=54.7 \pm 3.6 \%$ vs injury $=159.2 \pm 14.1 \%, p<0.0004, n=5)$ and a $59 \%$ increase compared to sham $($ sham $=100 \pm 10.0 \%$ vs injury $=159.2$ $\pm 14.1 \%, p<0.006, n=5$ ). The amount of phosphorylated CREB decreases to control values within $30 \mathrm{~min}$ of the impact. The contralateral hippocampus also showed a $75 \%$ increase in CREB phosphorylation 5 min after injury compared to sham-injured animals $(n=2)$. Increases in phosphorylation are also seen in the cortex surrounding the site of injury (Fig. $2 B$ ). However, the magnitude of changes in CREB phosphorylation in the cortex was variable. This variability could be due to the proximity of the cortical samples to the site of craniotomy. Both the hippocampal and cortical data show an increase in phosphorylation of CREB in the sham-injured animals as compared to naive. Sham injury involves surgery and craniotomy, which is diffuse mild injury. Western blots done using the same samples and an antibody (Yamamoto et al., 1988 ) that detects total CREB protein (Fig. 2C,D) show that there is no significant change in the total amount of the protein within $1 \mathrm{hr}$ of the impact. However, there is an average of about a $35 \%$ decrease in the total amount of CREB protein $(n=3)$ in the hippocampus at $3 \mathrm{hr}$ after the impact compared to naive animals. The significance of this decrease in total 
A. Hippocampal

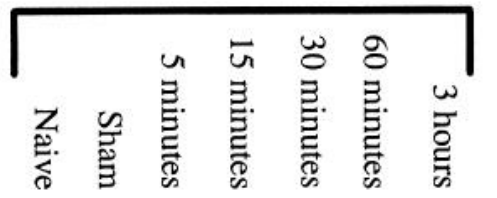

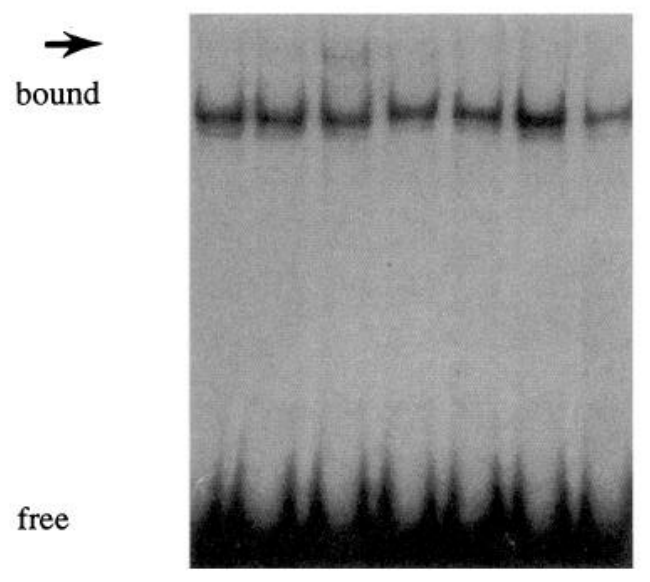

B.
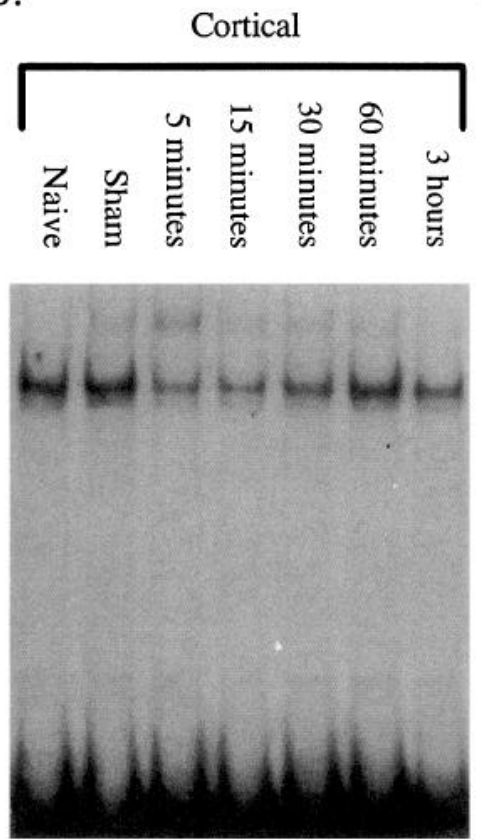

C.

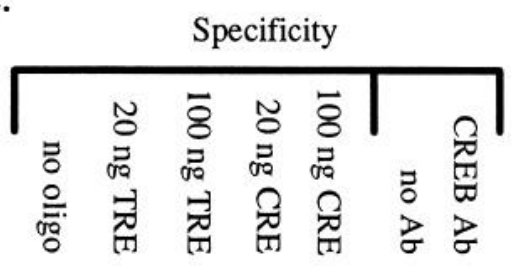

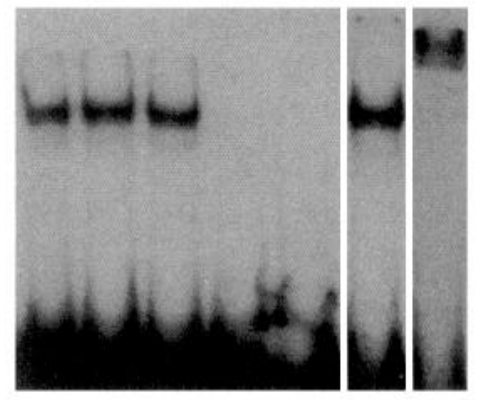

Figure 3. Gel-retardation assays for CREB using a probe containing the CRE sequence. A, Time course for CREB phosphorylation in the ipsilateral hippocampal nuclear extracts. Gel-retardation assays using $4 \mu \mathrm{g}$ of nuclear extracts were carried out as described in Materials and Methods. The addition of $1 \mu \mathrm{g}$ of phosphoCREB antibody to the reaction mixture results in a supershifted band. The supershifted band is caused by the binding of the antibody to the phosphorylated CREB protein, thus slowing its migration. The arrow indicates the migration of the supershifted band which is maximal $5 \mathrm{~min}$ after the injury. $B$, Time course for CREB phosphorylation in cortical nuclear extracts. Supershift assays were carried out as in $A$. The arrow indicates the migration of the supershifted band which is maximal at 5 min following injury. $C$, Gel-retardation assays showing the specificity of the retarded band. The first lane shows the retardation of the CRE probe caused by the binding of CREB proteins from the 15 min cortical nuclear extract without the addition of any antibodies or competitor oligonucleotides. The retarded band can be specifically inhibited by an excess of a CRE sequence containing oligonucleotide. An oligonucleotide containing the TRE sequence failed to inhibit binding. The inclusion of an antibody which detects CREB proteins regardless of their phosphorylation state results in a complete shift of the retarded band.

CREB in the ipsilateral hippocampus has not yet been investigated.

\section{Increased CREB phosphorylation by gel-retardation assay}

We performed gel-retardation assays using equal amounts of nuclear extracts prepared from the ipsilateral hippocampus and the cortex surrounding the site of injury of control and experimental animals. Addition of the phosphoCREB antibody to the gel-retardation reaction mixture causes a supershift of a band whose intensity is increased $5 \mathrm{~min}$ after cortical impact (Fig. 3A,B). As seen in the Western blots, the sham-injured animal shows an increase in CREB phosphorylation as compared to the naive animal. In addition, the increased intensity of the supershifted band at $5 \mathrm{~min}$ following injury is also consistent with the enhanced CREB phosphorylation seen by Western blotting (Fig. $3 A, B)$. However, the amount of phosphorylated CREB detected by gel retardation is lower than that detected by Western blot, presumably due to some dephosphorylation during the room temperature incubation with the CRE probe and antibodies. Figure $3 C$ shows the gel retardation using the nuclear extract prepared from the cortex of an injured animal $15 \mathrm{~min}$ after the impact. The first lane in Figure $3 C$ shows the retardation caused by CREB binding to the CRE oligonucleotide in the absence of any antibodies or competitor oligonucleotides. Inclusion of excess cold CRE oligonucleotides (obtained from the $c$-fos promoter sequence) blocks the binding of the CREB protein to the radioactive CRE band. Excess TRE (TPA response element, also referred to as AP-1 binding element) or HSE (heat shock ele- ment) oligonucleotides had no effect on the CRE binding. In addition, inclusion of an antibody that detects total CREB regardless of its phosphorylation state causes a supershift of the entire gel-retarded band. This indicates that the shift is caused by binding of CREB-related proteins. We next examined the spatial distribution of CREB phosphorylation in the hippocampus following cortical impact.

\section{Increased phosphoCREB immunoreactivity in the hippocampus}

The spatial distribution of phosphorylated CREB in the hippocampus was examined $5 \mathrm{~min}$ after injury in naive, sham, and injured animals as described in Materials and Methods (Fig. 4). Very little immunoreactivity was observed in the naive animal, suggesting a low basal level of CREB phosphorylation. The sham animal had a similar low level of immunostaining except in the CA2 subfield. In contrast, the injured animal had a marked increase in immunostaining in the dentate gyrus and to a lesser degree in the CA1, CA2, and CA3 subfields. When immunostaining was carried out using an antibody for total CREB proteins, no significant differences were seen (data not shown). In the absence of primary antibodies, no specific signal was detected. These data are consistent with results from Western blots described above. The phosphorylation of the CREB protein activates the transcription of genes containing the CRE sequence such as $c$-fos. We next investigated the expression of c-Fos and the AP-1 complex. 


\section{Naive}

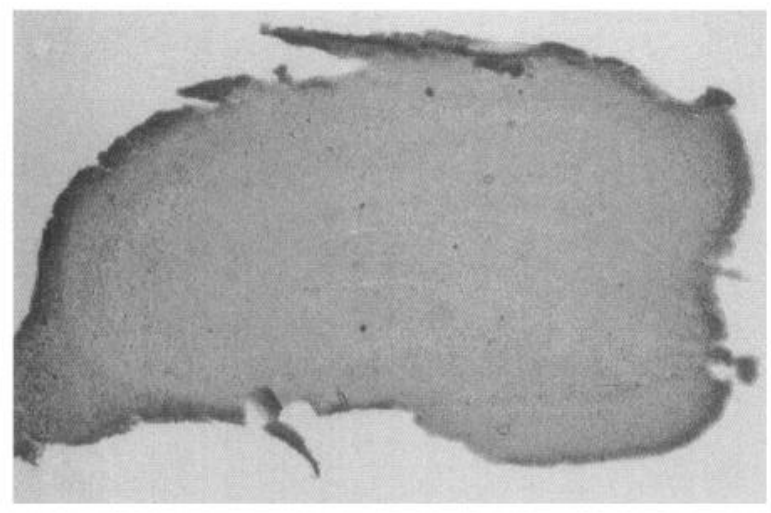

Sham

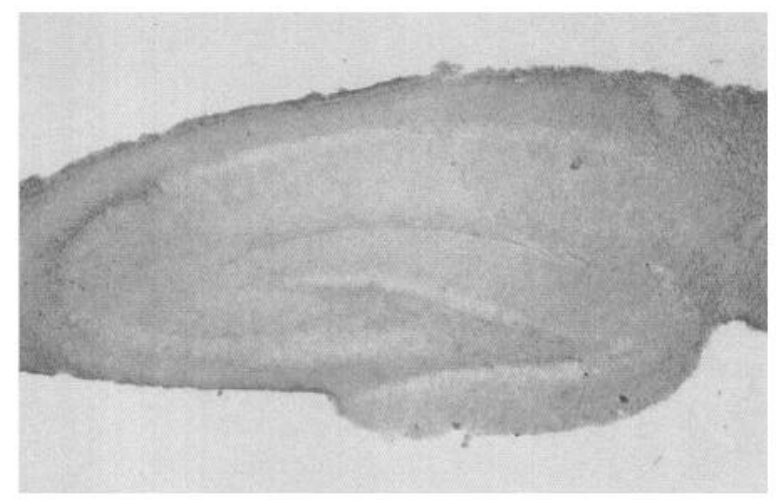

Injured

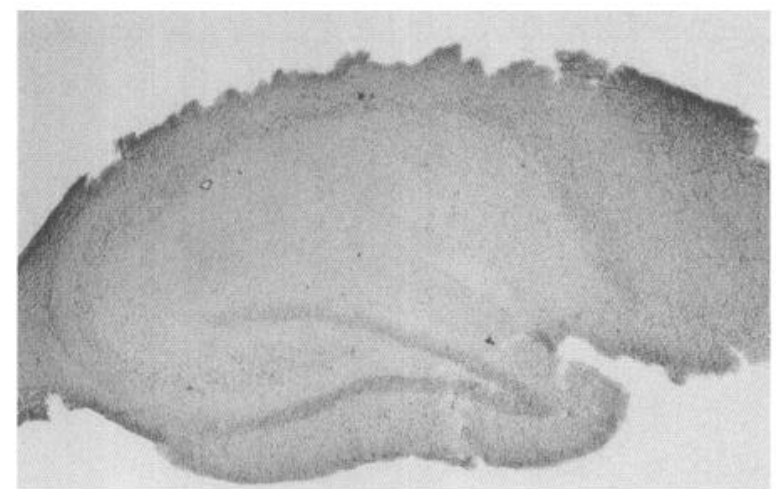

Figure 4. Immunohistochemical localization of phosphoCREB protein in the hippocampus after cortical impact. The hippocampi from experimental and control animals were removed quickly $5 \mathrm{~min}$ after cortical impact. The tissues were fixed in paraformaldehyde and sectioned for immunohistochemistry as detailed in Materials and Methods. Increases in the phosphoCREB immunoreactivity are seen in the dentate gyrus and to a lesser degree in the CA1, CA2, and CA3 subfields of the hippocampus. Some immunoreactivity is also detected in the CA2 subfield of the sham-injured animals.

\section{Expression of c-Fos and c-Jun following cortical impact}

Western blots using an antibody to c-Fos were performed using the nuclear extracts prepared from naive, sham, and injured animals. c-Fos protein is induced $1 \mathrm{hr}$ after the cortical impact and persists up to $3 \mathrm{hr}$ (Fig. $5 A, B$ ). The time course of c-Fos induction is consistent with it being activated by CREB. However, Western blot studies using a c-Jun-specific antibody showed no change in the expression of the c-Jun protein at the time points examined (data not shown).

\section{Increased AP-1 binding following cortical impact}

Gel-retardation assays were carried out using the TRE sequence as a probe to determine the amount of AP-1 induced following cortical impact. Nuclear extracts from both the hippocampus and cortex show minimal gel retardation up to $30 \mathrm{~min}$ following trauma (Fig. 6A,B). At $60 \mathrm{~min}$, however, a significant increase in the amount of gel-retarded TRE is seen. As seen in the c-Fos Western blot, the level of AP-1 is still increased at $3 \mathrm{hr}$. The first lane in Figure $6 C$ shows the binding of the $1 \mathrm{hr}$ hippocampal nuclear extract without the addition of any antibodies or competitor oligonucleotides. Competition of the gel-retarded band with excess TRE oligonucleotides (obtained from SV40 promoter) results in the elimination of the retarded band. Competition with excess HSE oligonucleotides had no affect. Supershift assays done with the c-Fos antibody result in the shift of the retarded band indicating the presence of $\mathrm{c}-\mathrm{Fos}$ proteins in the AP-1 complex.

\section{Spatial pattern for c-Fos expression}

The spatial pattern of c-Fos induction was examined using immunohistochemistry. c-Fos protein is induced both in the ipsiand contralateral hippocampi and in the cortex surrounding the site of impact (Fig. 7). The expression of c-Fos is increased in the dentate gyrus, CA2 and CA3 subfields, and, to a lesser extent, in the CAl region of the ipsilateral hippocampus $1 \mathrm{hr}$ after injury as compared to sham-injured animals (Fig. 7A). The pattern of c-Fos expression we detected in this model of brain injury differs from previously reported c-Fos induction in which an increase in the number of immunopositive neurons was detected in the CA1 region following fluid percussion brain injury (Phillips and Belardo, 1992). Increases in c-Fos immunoreactivity were also seen in the contralateral hippocampus (Fig. 7B). However, the level of c-Fos expression in the CAl was higher than that seen in the ipsilateral hippocampus. In the cortex surrounding the site of injury, increased c-Fos expression can again be seen (Fig. $7 \mathrm{C}$ ). The induction of this protein follows the increased phosphorylation of CREB protein described above. Moreover, the spatial distribution of c-Fos immunoreactivity in the ipsilateral hippocampus suggests that the $c$-fos gene is likely to be induced by CREB phosphorylation.

\section{Discussion}

The results presented in this report indicate that lateral cortical impact in rats produces motor performance and spatial memory deficits similar to that observed in other models of TBI (McIntosh et al., 1987; Dixon et al., 1991; Smith et al., 1991; Hamm et al., 1992). We have identified a component of the signal transduction pathways which are activated following cortical impact injury that may play a role in the observed behavioral deficits. The transcription factor CREB is a key component of this pathway and is activated by phosphorylation on serine ${ }^{133}$ in response to increases in levels of intracellular cAMP and/or calcium. Us- 
A.

$$
\text { Hippocampal }
$$

\begin{tabular}{|c|c|c|c|c|c|c|}
\hline 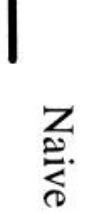 & $\begin{array}{l}\mathscr{N} \\
\hat{0}\end{array}$ & 品 & 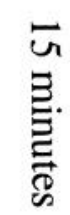 & 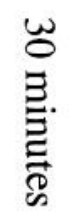 & 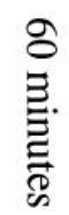 & $\begin{array}{l}\omega \\
\bar{\sigma} \\
\underline{\vdots}\end{array}$ \\
\hline
\end{tabular}

$49.5 \mathrm{kDa}---$
B.

\section{Cortical}

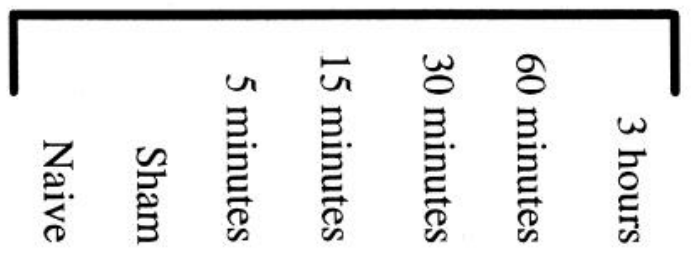

Figure 5. Increased expression of the c-Fos protein after cortical impact. A, A representative Western blot showing the time course of induction of the c-Fos protein in the ipsilateral hippocampus following injury. Nuclear extracts were prepared and separated as described in Material and Methods and the legend to Figure $2 \mathrm{~A}$. The level of c-Fos increases dramatically $1 \mathrm{hr}$ after injury and stays elevated in the $3 \mathrm{hr}$ sample. The arrow points to the migration of the Fos proteins. $B$, A representative Western blot showing the time course of induction of the c-Fos protein in the cortex surrounding the site of injury. The level of c-Fos in the cortical tissue is also dramatically elevated in the 1 and $3 \mathrm{hr}$ samples. The arrow points to the migration of the Fos proteins.

A.

Hippocampal

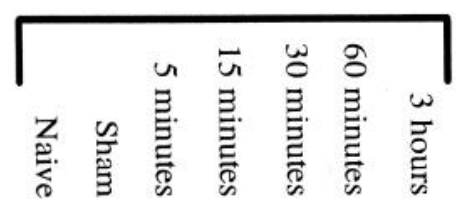

bound

free
B.

Cortical
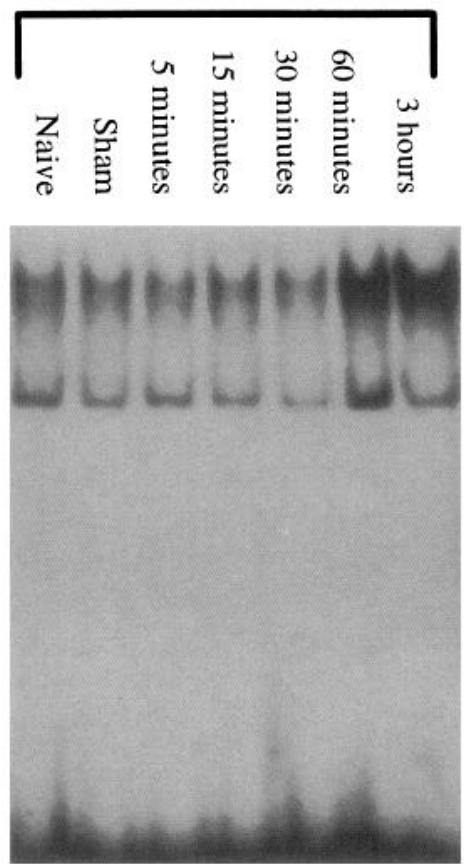

C.

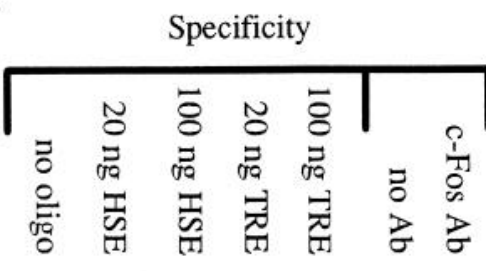

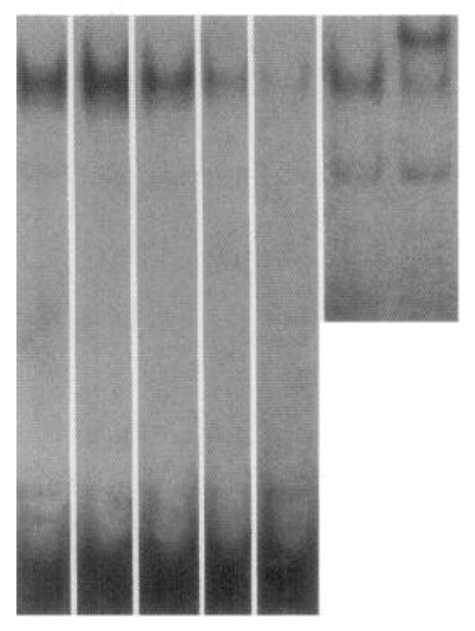

Figure 6. Gel-retardation assays for the AP-1 complex using the TRE sequence from metallothionein gene promoter as a probe. A, Time course for AP-1 induction in the ipsilateral hippocampal nuclear extracts. Gel-retardation assays using $4 \mu \mathrm{g}$ of nuclear extracts were carried out as described in Materials and Methods. The level of the AP-1 complex is minimal up to 30 min after injury. At 60 min, however, a dramatic increase in the level of AP-1 binding can be seen which continues to be elevated in the $3 \mathrm{hr}$ sample. These results are consistent with the increases in c-Fos immunoreactivity seen by Western blot. B. Time course for AP-1 induction in the cortical nuclear extracts. As seen in the ipsilateral hippocampus, the level of AP-1 binding increases dramatically at $60 \mathrm{~min}$ and remains elevated at $3 \mathrm{hr}$. $C$, Gel-retardation assay showing the specificity of the gel-retarded band. The first lane shows the level of AP-1 binding in the $1 \mathrm{hr}$ hippocampal nuclear extract without the addition of any antibodies or competitor oligonucleotides. The retarded band can be specifically inhibited by an excess of a TRE-containing oligonucleotide from SV40 promoter. An oligonucleotide containing the HSE sequence failed to inhibit binding. The inclusion of an antibody which detects c-Fos proteins results in a supershift of the retarded band, indicating the involvement of this protein in the AP-1 complex. 
A.

\section{Sham}

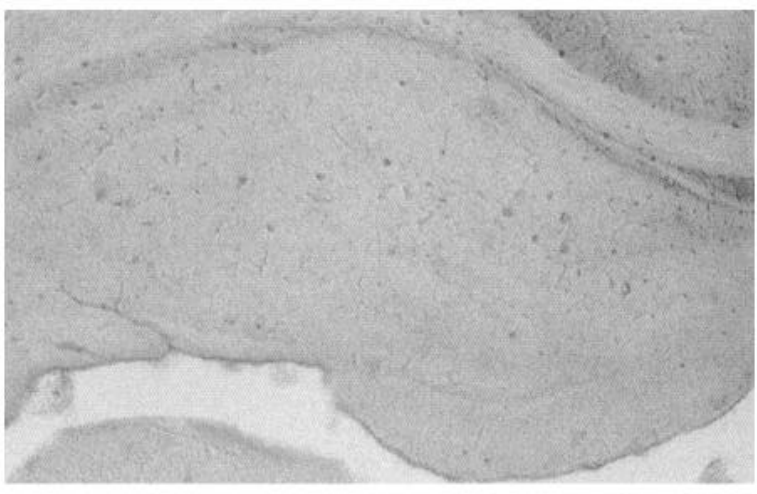

B.

\section{Sham}

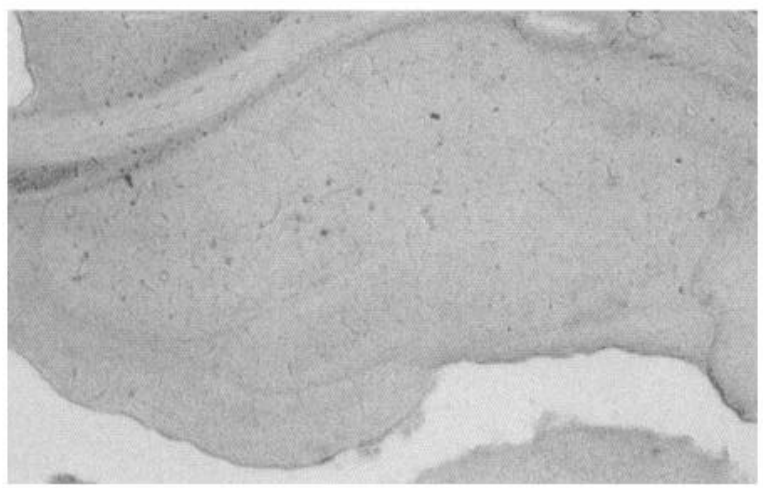

C.

\section{Sham}

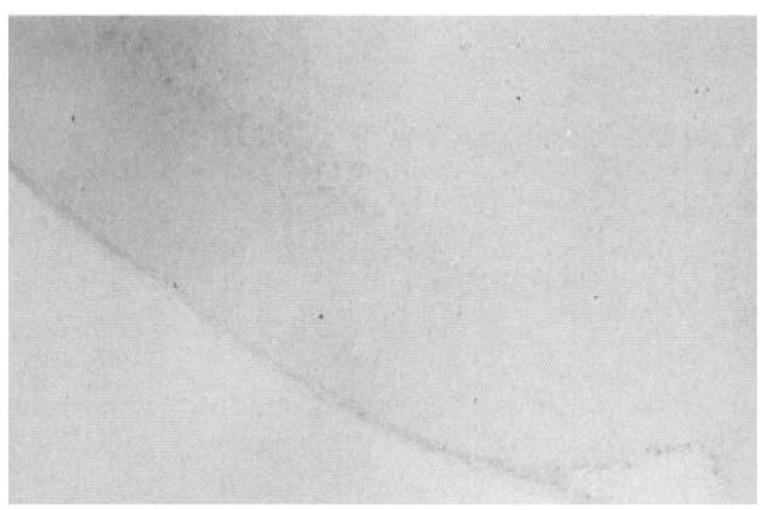

\section{Injured}

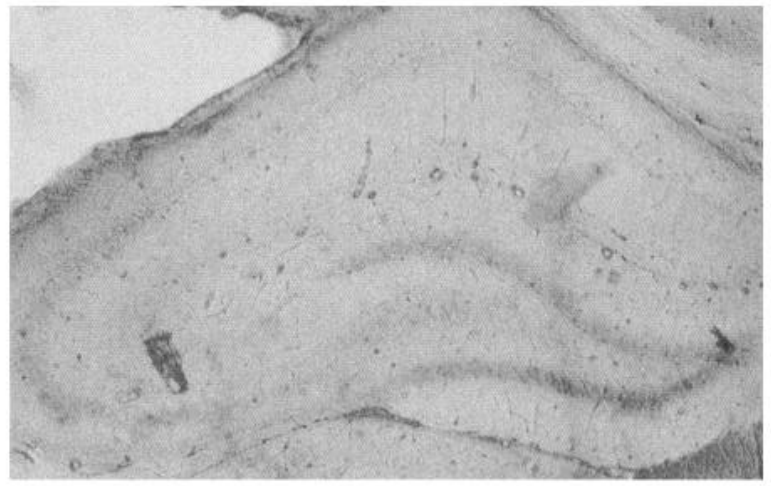

\section{Injured}

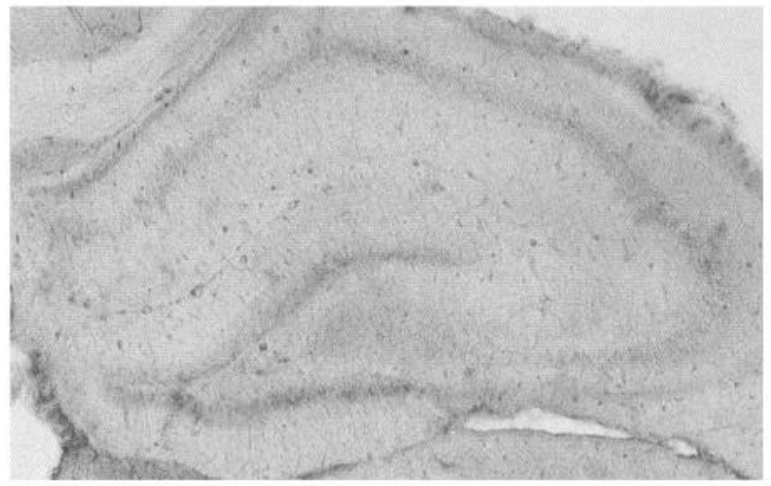

\section{Injured}

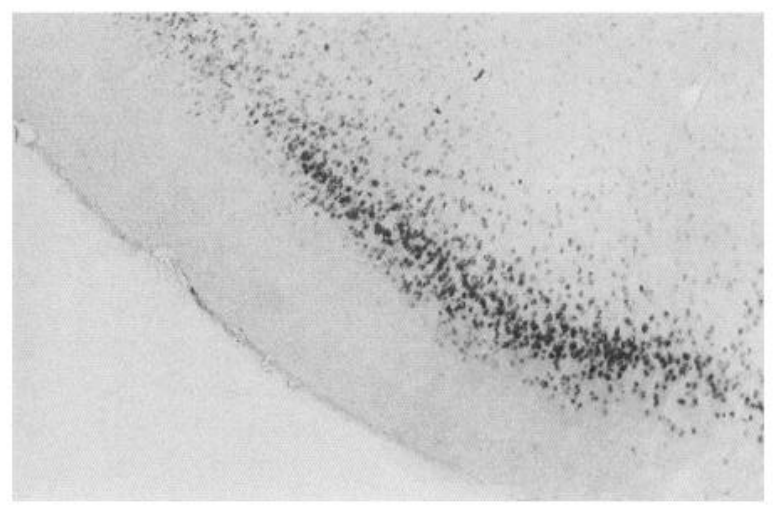

Figure 7. Spatial organization of the increased expression of c-Fos in the hippocampus and cortex following cortical impact. A, Photographs of the ipsilateral hippocampus from sham-injured and cortically impacted animals, respectively. An increase in c-Fos immunoreactivity can be seen in the dentate gyrus, CA2, CA3, and, to a lesser extent, CA1 subfields of the hippocampus. $B$, Photographs of the contralateral hippocampus from sham-injured and cortically impacted animals, respectively. An increase in c-Fos immunoreactivity can be seen in the experimental animal in the dentate gyrus, CA1, CA2, and CA3. C, Photographs of the cortex surrounding the site of injury from sham-injured and cortically impacted animals, respectively, also show an increase in c-Fos immunoreactivity. 
ing an antihody that detects phosphorylated CREB, we show the time course for CREB phosphorylation and found it to be maximal in both the hippocampi and the cortex $5 \mathrm{~min}$ postinjury. Using intracardial perfusion, our initial attempt to obtain a spatial distribution of phosphorylated CREB by immunohistochemistry failed. This failure is most likely due to the time constraints imposed by the surgery, anesthesia, and perfusion. To circumvent these constraints, we quickly dissected out the hippocampus and submerged it in paraformaldehyde. Using this technique, we were able to show a spatial distribution of phosphorylated CREB protein following cortical impact. Increases in phosphorylation were seen in the dentate gyrus and to a lesser extent in the CA1, $\mathrm{CA} 2$, and CA3 subfields of the hippocampus. Subsequent to the phosphorylation of CREB protein, the Fos protein and the AP-1 complex are induced.

The majority of the input to the hippocampus occurs via the perforant path making synaptic connection with the dentate gyrus. Thus, following excessive neuronal excitation induced by TBI, it is likely that the granule cells of the dentate will be more active compared to the pyramidal cells of the CA1, CA2, and CA3 subfields. The immunostaining for phosphoCREB and c-Fos are markedly increased in the dentate gyrus, consistent with the signaling pathway to the hippocampus. Moreover, enhanced inmunoreactivity for phosphoCREB and subsequently $c$-Fos in the dentate gyrus suggest that c-Fos is induced by phosphorylation of the CREB protein. In the ipsilateral hippocampus, the c-Fos immunoreactivity is increased in the dentate, CA2, $\mathrm{CA} 3$, and, to a lesser extent, CA1 subfields. In the contralateral hippocampus, similar levels of c-Fos expression were observed as in the ipsilateral hippocampus, with the exception of the CA1 subfield where the expression was markedly enhanced. The bilateral expression of $\mathrm{c}$-Fos may result from our experimental protocol or by transsynaptic signal transduction through commissural pathways. As described in Materials and Methods, our model uses a bilateral craniotomy to produce coronal movement of the cortex. This results in higher magnitudes of injury on the ipsilateral compared to the contralateral side. Using fluid percussion injury, it has been observed that lower magnitudes of injury result in greater numbers of neurons in the CA1 subfield expressing the c-Fos protein (Phillips and Belardo, 1992). The enhanced expression in the CA1 subfield on the contralateral side may be due a lower level of injury or through a yet unidentified mechanism.

Increased CREB phosphorylation after cortical impact suggests the activation of protein kinase $\mathrm{A}$ and/or CaM kinase I and II. Several studies carried out both in vitro and in vivo have shown that the CREB protein can activate transcription of CREcontaining genes when phosphorylated on serine ${ }^{133}$ by either protein kinase A or CaM kinase 1 and II (Gonzalez et al., 1989; Dash et al., 1991; Sheng et al., 1991). In addition, the CREB protein has also been shown to be substrate for PKC and cascin kinase II (Yamamoto et al., 1988; Dash et al., 1991). However, the in vivo significance of PKC or casein kinase II phosphorylations is unclear. Intracellular calcium concentrations have been shown to increase following injury (Fineman et al., 1993). The elevated calcium levels would directly activate CaM kinase II and $\mathrm{PKC}$ and indirectly activate protein kinase A via stimulation of calcium-sensitive adenyl cyclase. Activation of these kinases could lead to the phosphorylation of CREB on serine ${ }^{133}$. Our preliminary results indicate that CaM kinase $\mathrm{II}$ is activated and the amount of autophosphorylated (which is independent of cal- cium and calmodulin for its activity) kinase is increased 5 min after cortical impact.

Both the hippocampal and cortical Western blots as well as the immunohistochemistry show an increase in phosphorylation of CREB in the sham-injured animals as compared to naive. The densitumetric analysis of the phosphoCREB Western blots indicates that sham injury increases phosphorylation by $82.8 \%$ and the injury enhances phosphorylation by $59.2 \%$ over the sham. Sham injury involves surgery and craniotomy, which is likely a diffuse mild injury. It is possible that, like c-Fos, the phosphorylation of CREB may be more robust at lower injury levels. However, the Western blots show a relatively higher degree of phosphorylation in the sham as compared to the immunohistochemistry. This discrepancy could arise from the nonquantitative nature of immunohistochemistry, further complicated by the variability of CREB phosphorylation detected in sham-injured animals.

The total CREB as detected by Western blot did not change up to $1 \mathrm{hr}$ postinjury in the hippocampus. However, at $3 \mathrm{hr}$, there was a $35 \%$ decrease in the amount of total CREB. The initial phosphorylation of CREB would initiate a cascade of CRE-containing gene induction. Some of these gene products or CREBrelated inhibitory proteins such as CREM (cAMP responsive element modulating protein) could downregulate the expression of CREB (Foulkes et al., 1991). The significance of this decrease and its contribution to the neurological impairments is not known at present.

Our data do not establish a causal link between phosphorylation of CREB and the subsequent induction of c-Fos with the observed performance deficits. c-Fos expression has been reported during various types of neuronal plasticities including learning, postnatal development, and neuronal regeneration following injury (Maleeva et al., 1989; Doucet et al., 1990; Morgan and Curran, 1991; Nikolaev et al., 1992). All these processes involve synaptic reorganization which may depend on growth and sprouting of neuronal processes. While the functional significance of c-Fos induction following TBI is unclear at the prescnt, it is possible that $c$-fos cxpression is a stress response whose purpose is to protect cells from further damage and could participate in the subsequent regeneration process (for review see Doucet et al., 1990). Alternatively, $c$-fos expression in some cells may be involved in the death of these cells by apoptotic mechanisms (Colotta et al., 1992; Smeyne et al., 1993). Neuronal cell loss, inappropriate sprouting, or excessive stimulation of neurons could produce post-traumatic memory dysfunction.

Associated with the induction of c-Fos proteins, increased amounts of the AP-1 complex would activate target genes containing the TRE sequence, resulting in physiological changes. For example, the NGF gene and the neuropeptide proenkephalin and prodynorphin genes are known to contain the TRE sequence (Gall and Isackson, 1989; Sonnenberg et al., 1989b; Naranjo et al., 1991). In addition, the combinatorial complex formation between Fos and Jun family members may have distinct effects in different cell types. Further research is necessary to identify these target genes and examine their functional significance by blocking their expression either by homologous recombination or antisense oligonucleotides.

\section{References}

An G, Lin T-N, Liu J-S, Xue J-J, He Y-Y, Hsu CY (1993) Expression of $c$-fos and $c$-jun family of genes after focal cerebral ischemia. Ann Neurol 33:457-464. 
Angel P, Allegretto EA, Okino ST, Hattori K, Boyle WJ, Hunter T, Karin M (1988) Oncogene jun encodes a sequence-specific trans-activator similar to AP-1. Nature 332:166-171.

Bohmann D, Bos TJ, Admon A, Nishimura T, Vogt PK, Tjian R (1987) Human proto-oncogene $c$-jun encodes a DNA binding protein with structural and functional properties of transcription factor AP-1. Science 238:1386-1392.

Colotta F, Polentarutti N, Sironi M, Mantvani A (1992) Expression and involvement of $c$-fos and $c$-jun protooncogenes in programmed cell dcath induced by growth factor deprivation in lymphoid cell lines. $\mathrm{J}$ Biol Chem 267:18278-18283.

Dash PK, Moore AN (1993) A peptide containing the leucine zipper domain specifically inhibits CREB binding and transcription. Cell Mol Biol 39:35-43.

Dash PK, Karl KA, Colicos MA, Prywes R, Kandel ER (1991) cAMP response element-binding protein is activated by $\mathrm{Ca} 2+$ /calmodulinas well as cAMP-dependent protein kinase. Proc Natl Acad Sci USA 88:5061-5065.

Dixon CE, Clifton GL, Lighthall JW, Yaghmai AA (1991) A controlled cortical impact model of traumatic brain injury in rat. J Neurosci Methods 39:253-262

Doucet JP, Squinto SP, Bazan NG (1990) Fos-Jun and the primary genomic response in the nervous system. Mol Neurobiol 4:27-55.

Fineman I, Hovda D, Smith M, Yoshino A, Baker D (1993) Concussive brain injury is associated with a prolonged accumulation of calcium: a ${ }^{45} \mathrm{Ca}$ autoradiographic study. Brain Res 624:94-102.

Foulkes NS, Borrelli E, Sassone-Corsi P (1991) CREM gene: use of alternative DNA-binding domains generates multiple antagonists of cAMP-induced transcription. Cell 64:739-749.

Frey U, Huang YY, Kandel ER (1993) Effects of cAMP stimulate a late stage of LTP in hippocampal CA1 neurons. Science 260:16611664.

Gall CM, Isackson PJ (1989) Limbic seizure increases neuronal production of messenger RNA for nerve growth factor. Science 245:758761

Ginty DD, Kornhauser JM, Thompson MA, Bading H, Mayo KE, Takahashi JS, Greenberg ME (1993) Regulation of CREB phosphorylation in the suprachiasmatic light and a circadian clock. Science 260: 238-241.

Goelet P, Castellucci VF, Schacher S, Kandel ER (1986) The long and short of long-term memory: a molecular approach. Nature 322:519522.

Gonzalez GA, Montminy MR (1989) Cyclic AMP stimulates somatostatin gene transcription by phosphorylation of CREB at serine 133 . Cell 59:675-680.

Grant SG, O'Dell TJ, Karl KA, Stein PL, Soriano P, Kandel ER (1992) Impaired long-term potentiation, spatial learning, and development in fyn mutant mice. Science 258:1903-1910.

Hamm RJ, Dixon CE, Gbadebo DM, Singha AK, Jenkins LW, Lyeth BG, Hayes RL (1992) Cognitive deficits following traumatic brain injury produced by controlled cortical impact. J Neurotrauma 9:1120 .

Harlow E, Lane D (1988) Antibodies: a laboratory manual. Cold Spring Harbor, NY: Cold Spring Harbor Laboratory.

Hawley RJ, Scheibe RJ, Wagner JA (1992) NGF induces expression of the VGF gene through a cAMP response element. J Neurosci 12: 2573-2581.

Hayes RL, Jenkins LW, Lyeth BG (1992) Neurotransmitter-mediated mechanisms of traumatic brain injury: acetylcholine and excitatory amino acids. J Neurotrauma 1:S173-S187.

Hoeffler JP, Deutsch PJ, Lin J, Habener JF (1989) Distinct adenosine 3',5'-monophosphate and phorbol ester-responsive signal transduction pathways converge at the level of transcriptional activation by the interactions of the DNA-binding proteins. Mol Endocrinol 3:868880 .

Hymann S, Comb M, Lin Y, Pearlberg J, Green M, Goodman H (1988) A common trans-acting factor is involved in transcriptional regulation of neurotransmitter genes by cyclic AMP. Mol Cell Biol 8:42254233.

Kim KS, Lee MK, Carrol J, Joh TH (1993) Both the basal and induc- ible transcription of tyrosine hydroxylase gene are dependent upon a cAMP response element. J Biol Chem 268:15689-15695.

Kornhauser JM, Nelson DE, Mayo KE, Takahashi JS (1990) Photic and circadian regulation of $c$-fos gene in the hamster suprachiasmatic nucleus. Neuron 5:127-134.

Lee W, Haslinger A, Karin M, Tjian R (1987) Activation of transcription by two factors that bind promoter and enhancer sequences of the human metallothionein gene and SV40. Nature 325:368-372.

Maleeva NE, Ivolgina GL, Anokhin KV, Limborskaja SA (1989) Analysis of the expression of the $c$-fos protooncogene in the rat cerebral cortex during learning. Genetica 25:1119-1121.

McIntosh TK, Nobel L, Andrews B, Faden AI (1987) Traumatic brain injury in rat: characterization of a midline fluid-percussion model. CNS Trauma 4:119-134.

Montminy MR, Sevarino KA, Wagner JA, Mandel G, Goodman RH (1986) Identification of cAMP responsive element within rat somatostatin gene. Proc Natl Acad Sci USA 83:6682-6686.

Morgan JI, Curran T (1991) Stimulus-transcription coupling in the nervous system: the inducible proto-oncogenes fos and jun. Annu Rev Neurosci 14:421-451

Morris RGM, Anderson F, Iynch GS, Baudry M (1986) Selective impairment of learning and blockade of long-term potentiation by an $N$-methyl-D-aspartate receptor antagonists, AP5. Nature 319:774776.

Naranjo JR, Mellstrom B, Achaval M, Sassone-Corsi P (1991) Molecular pathways of pain: Fos/Jun-mediated activation of a noncanonical AP-1 site in the prodynorphin gene. Neuron 6:607-617.

Nikolaev E, Kaminska B, Tischmeyer W, Matthies H, Kaczmarek L (1992) Induction of expression of genes encoding transcription factors in rat brain elicited by behavioral training. Brain Res Bull 128: $479-484$

O'Dell TJ, Kandel ER, Grant SG (1991) Long-term potentiation in the hippocampus is blocked by tyrosine kinase inhibitors. Nature 353: $558-560$

Phillips LL, Belardo ET (1992) Expression of c-fos in the hippocampus following mild and moderate fluid percussion brain injury. J Neurotrauma 9:323-333.

Rauscher FJ III, Voulalas PJ, Franza BR Jr, Curran T (1988) Fos and Jun bind cooperatively to the AP-1 site: reconstitution in vitro. Genes Dev 2:1687-1699.

Sassone-Corsi P, Ransone LJ, Lamph WW, Verma IM (1988) Direct interaction between Fos and Jun nuclear oncoproteins: role of the "leucine zipper" domain. Nature 336:646-651.

Sheng M, Greenberg ME (1990) The regulation and function of $c$-fos and other immediate early genes in the nervous system. Neuron $4: 477-485$

Sheng M, Thompson MA, Greenberg ME (1991) CREB: a Ca ${ }^{2+}$-regulated transcription factor phosphorylated by calmodulin-dependent kinases. Science 252:1427-1430.

Silva AJ, Stevens CF, Tonegawa S, Wang Y (1992a) Deficient hippocampal long-term potentiation in $\alpha$-calcium-calmodulin kinase II mutant mice. Science 257:201-206.

Silva A, Paylor R, Wehner JM, Tonegawa S (1992b) Impaired spatiallearning in calcium-calmodulin kinase II mutant mice. Science 257: 206-211.

Smeyne RJ, Vendrell M, Hayward M, Baker SJ, Miao GG, Schilling K, Robertson LM, Curran T, Morgan JI (1993) Continuous c-fos expression precedes programmed cell death in vivo. Nature 363:166169.

Smith DH, Okiyama K, Thomas MJ, Claussen B, McIntosh TK (1991) Evaluation of memory dysfunction following experimental brain injury using the Morris water maze. J Neurotrauma 8:259-269.

Sonnenberg JL, Macgregor-Leon PF, Curran T, Morgan JI (1989a) Dynamic alterations occur in the levels and composition of transcription factor AP-1 complexes after seizure. Neuron 3:359-365

Sonnenberg JL, Rausher FJ III, Morgan JI, Curran T (1989b) Regulation of proenkephalin by fos and jun. Science 246:1622-1625.

Yamamoto KK, Gonzalez GA, Biggs WH III, Montminy MR (1988) Phosphorylation-induced binding and transcriptional efficacy of nuclear factor CREB. Nature 334:494-498. 